\title{
Under the Microscope: Dr. Jason McLellan
}

\section{by Laura Wilson and Dara Laczniak, MSA Student Council}

Editor's Note: This month and in the coming months, Microscopy Today, in collaboration with the Microscopy Society of America Student Council, is sitting down with this year's

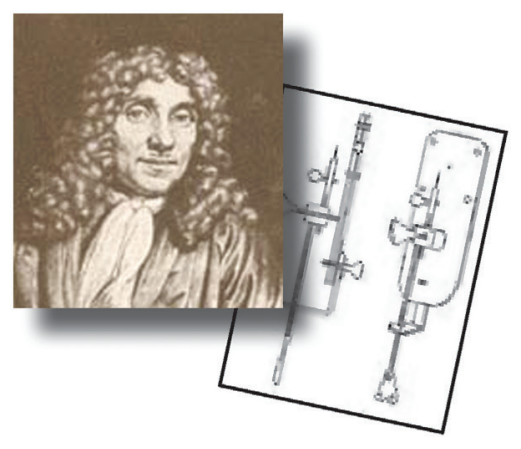
Microscopy \& Microanalysis plenary speakers to discuss their incredible work and the paths that led them to findings that impact the world. We hope this will further connect our community in a time where connection has been reimagined. This series of interviews, beginning with Dr. Jason McLellan, explores not only the science, but the journey of the scientists themselves.

\section{Cameron Varano, Pioneers editor}

The Pennsylvania State University, 201 Old Main, University Park, PA 16802

cvarano@psu.edu

For nearly a year and a half, the SARS-CoV-2 virus has plagued our lives. As microscopists, many of us have probably wondered - and Googled - what this tiny yet vicious respiratory virus looks like. Thanks to research by Dr. Jason McLellan, a faculty member in the Department of Molecular Biosciences at the University of Texas and a Biological Science Plenary speaker at the upcoming virtual M\&M conference, we have a detailed understanding. Dr. McLellan and his lab group have been working on understanding the structure and function of coronavirus spike proteins (which allow the virus to enter host cells and cause infection) and have designed novel vaccine antigens that are in four of the leading COVID-19 vaccines. His group has determined the cryo-EM structure of the SARS-CoV-2 spike protein and used that information to design second-generation spikes that are more stable and express better than initial variants. His work highlights the importance of basic science research prior to pathogen emergence and demonstrates how structure-based design can be used to rapidly produce vaccine antigens. We had the chance to speak with Dr. McLellan about his research and advice for young microscopists.

\section{You were one of the first people to see what the RSV} (respiratory syncytial virus, a common respiratory virus that is a lead cause of morbidity and mortality in children under the age of 5) looks like. How did you make the connection from RSV to SARS-CoV-2 in determining how to stabilize the virus' spike proteins?

RSV and coronaviruses are enveloped RNA viruses, and they require a specific type of protein called a class 1 viral fusion protein to enter cells. These proteins are related to some common ancestor, so there's an underlying conservation of folds. The coronavirus spike is the largest of the class 1 viral fusion proteins, and RSV F is one of the smaller ones, but there's an overall refolding event that occurs and some overall structural homology. We were fortunate that we learned a lot from comparing the RSV F protein in its pre- and post-fusion structures, figuring out how to lock it in the pre-fusion, and then we were able to apply a lot of those principles (both from my lab and from others in the field) to coronaviruses.

Is there anything about your lab's SARS-CoV-2 research that you want to highlight?

Four of the major COVID-19 vaccines are all using a spike protein containing stabilizing mutations my lab developed. That's been pretty amazing, seeing something go from the lab into my own arm and being used across the world. I got into vaccine design with the hope of contributing to the development of one vaccine, and I think we have. We're also working on some new stuff with new viruses. We've also been working on, for SARS-CoV-2, a second generation of our stabilized spike that's geared for low- and middle-income countries; it's been really exciting to see some of the technology helping the rest of the world that desperately needs vaccines. It's a cool technology that involves our spike and can be grown in eggs, allowing all these countries to make their own SARS-CoV-2 vaccine.

What have you found to be the most effective way to communicate the importance of vaccines/science/research to inspire the next generation of scientists?

This past year in particular I have done lots of science communication and interviews, but for graduate students or those with a strong science background, in general, you have to simplify it a little bit in order to make it accessible, point to concrete examples of instances where the power of structural biology and vaccine design have led to new advances, possibly new vaccines moving into clinical trials. I also like to use cool visuals (Zoom background, 3D-printed models). I try to do as much as I can. It's been great this past year, that there have been opportunities for scientists to actually speak and be on $\mathrm{CNN}$ and other things. It's been nice to see a lot of scientists and peers and colleagues on shows and having opinions; they are the experts. 


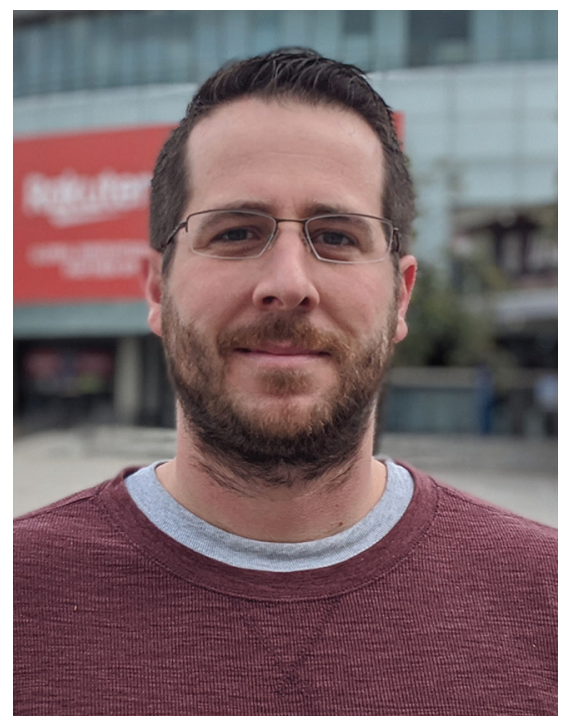

Figure 1: Dr. Jason McLellan, one of two Biological Science Plenary speakers at M\&M 2021.

What do you see as the future of microscopy/ bio-microscopy?

There will continue to be new developments in technology, new hardware and scopes. I think cryo-electron tomography (which produces high-resolution 3D images of samples) will continue to grow, single-particle experiments will become more prevalent, and technology advances will also require software, data handling, machine learning, and AI approaches. Ultimately, these advances in technology allow for new questions to be addressed, and it's all really exciting.

How was the transition from being a student in someone else's lab to running your own?

My advice would be to keep your doors open. A lot happens in 10 years; as people we grow and change and mature. Work hard, be smart, and get lucky! Those are the keys to being successful in science. You can't control how inherently smart you are, but you can make up for things by being really well read and knowledgeable, and you can control how hard you work, all of which increases the probability of good fortune finding you.

What are some of the differences in being a part of someone else's lab versus running your own lab?

I loved being a student and postdoc; I did experiments, I was in the lab every day, I was constantly thinking about them, getting excited to come in and see the gel from the night before. You basically don't have any responsibility other than yourself moving your project along. It's a pretty awesome time to just "science" and have fun. Now, as a PI, I essentially manage a small business, have lots of emails, I have to know all the different projects going on, I have expenses and incomes, I'm doing service. It's very different, like the difference between playing a sport and being asked to coach the sport.

Do you have advice for students looking for labs and how they find the right fit and PI?

We are developing resources at UT Austin, and there are also a lot of resources available, that is, some of the top journals

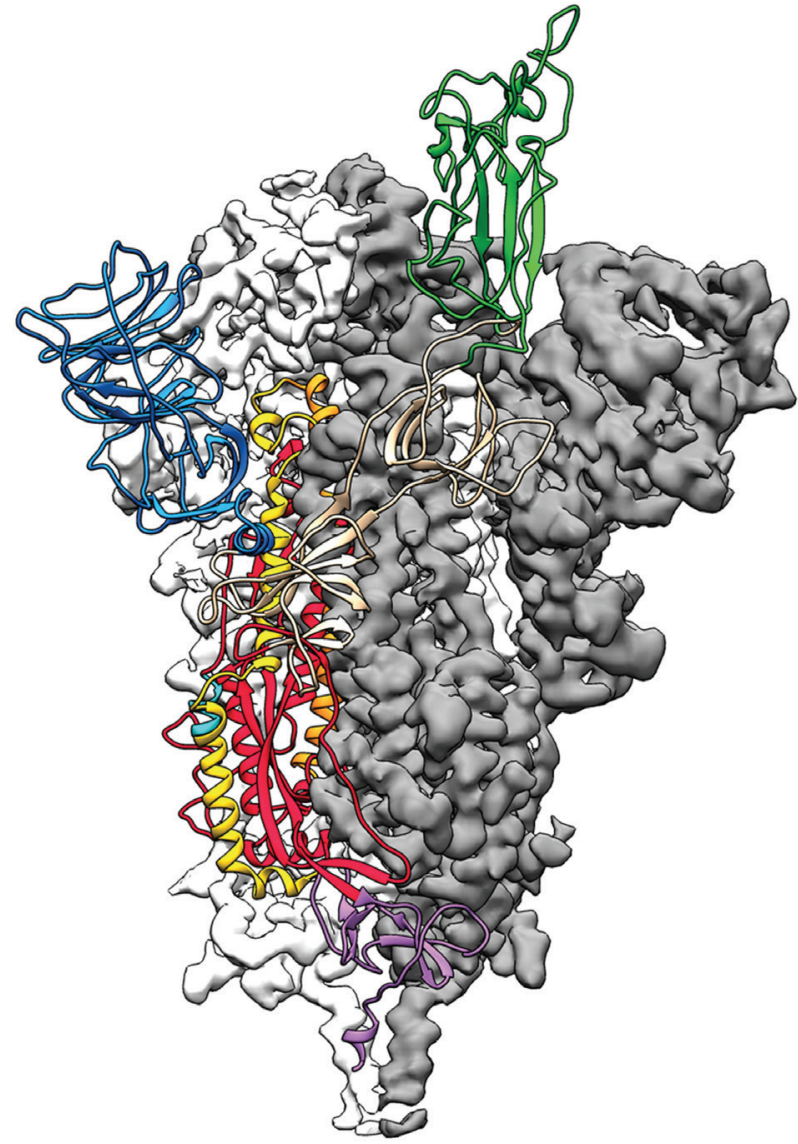

Figure 2: Model of the cryo-EM structure of the SARS-CoV-2 spike protein.

have articles about mentoring and mentorship, but it's more of a feel. There are some really nice forums that ask the right questions about mentoring. Communication is so critical. You want to meet with the PI, speak with them frequently, and make sure you're aligned.

Any advice to students for networking in this virtual world?

Get on Twitter! I think Twitter has been amazing during COVID. It's been people publishing preprints on bioRxiv, being peer-reviewed real-time in Twitter, people weighing in with thoughts and sharing ... I think Twitter has just been amazing. I'm following postdocs and grad students and thinking about having them in my lab; it's a way to get people to know you and see some of your personality, what papers you like to readand it's a really cool community.

\section{Any parting words for students?}

Find something you're passionate about and you love to do and try to make that your career. I love science; I love coming to work. Science opens up so many amazing doors, with traveling and being able to contribute to the knowledge base and overall human health. Just find what motivates you, what you're passionate about, and do everything you can to make that your career. 